\title{
POTENSI PEMANFAATAN ICT UNTUK PENINGKATAN MUTU PEMBELAJARAN SMA DI KOTA YOGYAKARTA
}

\author{
Herman Dwi Surjono dan Abdul Gafur \\ FT dan FISE Universitas Negeri Yogyakarta (email: hermansurjono@uny.ac.id)
}

\begin{abstract}
ICT Implementation Potentials in Public Senior High Schools in Yogyakarta City to Improve the Instructional Quality. This study aims to describe ICT implementation potentials for learning in terms of: (1) the level of the students' and staff's ICT competency, (2) the model employed in implementing ICT, and (3) the obstacles in implementing ICT. This study was a descriptive study involving 341 respondents consisting of students, teachers, ICT personnel, clerical staff, and principals. They were selected randomly from 11 public senior high schools in Yogyakarta City. The quantitative data were analyzed by descriptive statistics and the qualitative data by an inductive technique. The results show that there are 8 people $(2.3 \%)$ of very low level, 54 people (15.8\%) of low level, 115 people $(33.5 \%)$ of medium level, 128 people (37.5\%) of high level, and 36 people $(10.6 \%)$ of very high level. ICT has been systematically implemented through design, development, utilization, management, and evaluation. The obstacles in implementing ICT come from the lack of personnel, infrastructure, hardware, and software.
\end{abstract}

Keywords: Information and Communication Technology, ICT implementation, instructional quality.

\section{PENDAHULUAN}

Tujuan akhir pendidikan nasional secara umum adalah peningkatan sumber daya manusia (SDM) yang berkualitas seperti tercantum dalam pasal 3 UU No. 3 Th. 2003 tentang Sistem Pendidikan Nasional (Sisdiknas). Untuk mencapai tujuan tersebut, diperlukan adanya pendidikan dan pembelajaran yang efisien dan efektif, baik internal (sebanding tidaknya hasil pendidikan dengan biaya yang telah dikeluarkan) maupun eksternal (relevan atau berpengaruh tidaknya hasil pelaksanaan pendidikan dengan penghasilan lulusan setelah bekerja) (Loskheed \& Hanushek, 1996:299). Pendidikan kita belum me- muaskan. Efisiensi, efektivitas, dan kualitas belum memuaskan (Sidi, 2002:1).

Banyak faktor yang berpengaruh atau berperan dalam mencapai tujuan tersebut. Salah satu di antaranya adalah teknologi yang digunakan dalam kegiatan pendidikan dan pembelajaran. Teknologi pembelajaran yang dewasa ini aplikasinya berupa pemanfaatan proses dan produk teknologi komunikasi dan informasi (Information and communication technology/ICT) untuk memecahkan masalah-masalah pendidikan memiliki banyak manfaat atau keuntungan. Dengan memperhatikan keunggulan teknologi pembelajaran, dapat disusun strategi pemanfaatan yang tepat 
dan optimal untuk meningkatkan kualitas, efisiensi, dan efektifitas pendidikan dan pembelajaran pada berbagai tingkatan satuan pendidikan termasuk di SMA.

Secara sistematis sejalan dengan konsep dan prinsip bidang keilmuan teknologi pembelajaran sebagai induk TI/TIK/CT, penelitian ini ingin mendapatkan data lapangan pertama tentang tingkat kompetensi ICT SDM, kedua tentang potensi SMA sekota Yogyakarta dalam mengimplementasikan ICT yang antara lain meliputi kegiatan: (1) merancang/mendisain; (2) mengembangkan/memproduksi; (3) memanfaatkan; (4) mengelola; dan (5) mengevaluasi terhadap proses dan sumber pembelajaran berbasis TIK dalam rangka meningkatkan mutu pembelajaran; ketiga tentang hambaran-hambatan yang dihadapi dalam mengimplementasikan ICT. Dengan mengungkap permasalahan yang berhubungan dengan ketiga aspek tersebut, diharapkan dapat diketahui pula dukungan dan hambatan yang berkenaan dengan sumber daya manusia (SDM), infrastruktur, manajemen, dsb.

Output penelitian ini berupa deskripsi yang menggambarkan seberapa tinggi tingkat kompetensi ICT, potensi sekolah-sekolah di Yogyakarta dalam mendesain, mengembangkan, memanfaatkan, mengelola, dan mengevaluasi TIK, serta hambatan yang dihadapi dalam mengimplementasikan ICT. Hasil pemetaan tersebut diharapkan dapat digunakan sebagai bahan pertimbangan dalam mengambil kebijakan yang berkenaan dengan peningkatan mutu pendidikan di Yogyakarta, khususnya yang menyangkut pemanfaatan ICT untuk pembelajaran.

Roadmap penelitian ICT ini dapat dijelaskan sebagai berikut. Telah banyak penelitian dilakukan berkenaan dengan ICT. Beberapa contoh misalnya Mbangwana (2008) meneliti tentang "Pengenalan ICT di sekolah-sekolah dan kelas di Cameroon" untuk menjawab pertanyaan penelitian "Apakah pengenalan/pengintegrasian ICT di sekolah dapat berperan sebagai wahana dan dasar untuk menggerakkan reformasi pendidikan yang bermakna untuk bergeser dari "instructionism" yang bersifat didaktis ke "constructivism"? Hasil penelitian menunjukkan bahwa "The integration of ICT in Cameroon remains sporadic and without clear direction. Access to ICT by students and teachers has begun, yet its use supports traditional teaching rather than the shift to new roles and pedagogical practice". Penelitian lain yang dilakukan Guild (2006) lebih banyak menggali aspek-aspek yang berkenaan dengan e-learning sebagai bagian dari ICT. Tema-tema penelitiannya antara lain The current state of e-learning, Elearning success factors and priorities, future directions of e-learning, new e-learning modalities, etc.

Berbeda dengan penelitian di atas, penelitian ini dilaksanakan dengan menggunakan pendekatan yang sistematis dan sistemik sesuai dengan konsep dan prinsip teknologi pembelajaran sebagai supra system dari ICT dan elearning. Dalam penelitian ini, ingin diketahui potensi SDM di bidang ICT, potensi sekolah dalam mendisain, mengembangkan, memanfaatkan, mengelola dan mengevaluasi penerapan ICT. 
Jadi peta atau profil potensi sekolah tidak hanyamenyangkutpemanfaatan dalam arti sempit, tetapi juga menyangkut disain, pengembangan pemanfaatan, pengelolaan, dan penilaian/evaluasi sesuai dengan konsep teknologi pembelajaran mutakhir.

Konsep teknologi pembelajaran (instructional technology) mutakhir dapat dilihat dalam definisi yang dikeluarkan oleh Association for Educational Communications and Technology (AECT) sebagai berikut:"Instructional Technology is the theory and practice of design, development, utilization, management and evaluation of processes and resources for learning" (Seels \& Richey, 1994:10). Berdasar definisi tersebut, kawasan (domain) teknologi pembelajaran dapat dilihat pada Gambar 1.
Membantu proses belajar, memicu dan memacu, proses belajar, serta memberikan kemudahan atau fasilitas belajar merupakan tujuan Teknologi Pembelajaran. Tercapainya tujuan belajar berupa berubahnya pengetahuan, keterampilan, dan sikap secara relatif tetap yang diakibatkan oleh pengalaman, bukan karena kedewasaan atau pertumbuhan merupakan kriteria pokok keberhasilan pembelajaran. Hal ini sejalan dengan pengertian "learning refers to the relatively permanent change in a person's knowledge or behavior due to experience" (Mayer dalam Seels \& Richey, 1994: 12); atau "Learning is a change in human disposition or capability which persists over a period of time, and which is not ascribable to processes of growth" (Gagne, 1997:3).

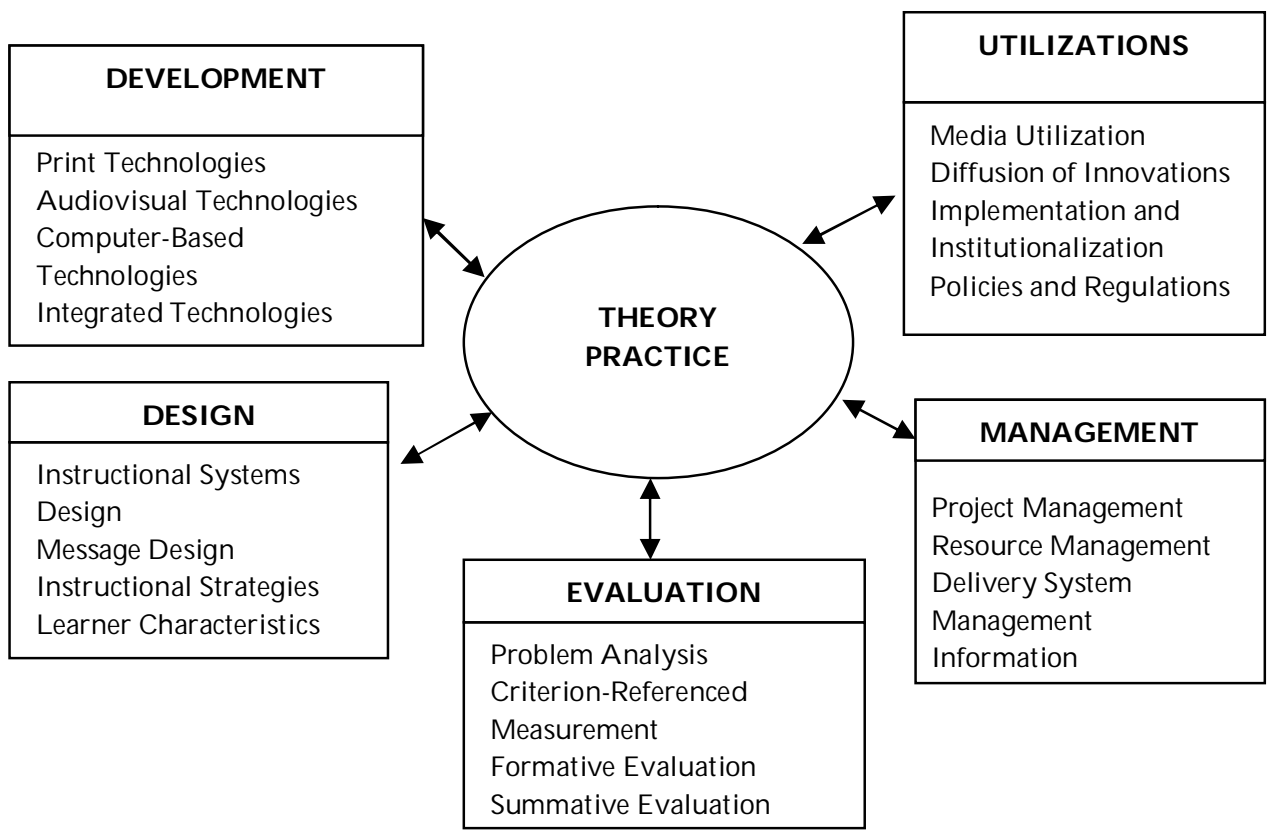

Gambar 1: The Domains of Instructional Technology

(Sumber: Seels \& Richey, 1994: 26) 
Dewasa ini istilah teknologi pembelajaran bergeser menjadi teknologi informasi, teknologi komunikasi, dan teknologi informasi dan komunikasi. UNESCO secara resmi menggunakan istilah Information and Communication Technology (ICT). Istilah tersebut merupakan gabungan dari dua konsep yaitu Information Technology dan Communication Technology.

Information Technology is the term used to describe the items of equipment (hardware) and computer program (software) that allow us to access, store, organize, manipulate, and present information by electronic means. Communication technology is term used to describe telecommunication equipment, through which information can be sought an accessed (Unesco, 2003:7).

Definisi tersebut sejalan dengan pendapat Labelle (2004:1) yang menyatakan bahwa "ICT means all equipment, processes, procedures, and systems used to provide and support information system (both computerized and manual) within an organization".

Di Indonesia pun kini istilah ICT yang digunakan oleh UNESCO tersebut diadopsi menjadi Teknologi Informasi dan Komunikasi (TIK). Istilah tersebut sebenarnya telah lama digunakan, yaitu sejak berdirinya Pusat Teknologi dan Komunikasi untuk Pendidikan (PUSTEKKOMDIBUD/DIKNAS) tahun 1970an.

Sejak dekade awal perkembangannya, telah dirasakan manfaat atau keuntungan teknologi pembelajaran. Hal ini dapat dilihat dari hasil identifikasi Presidential tahun 1969 yang menyim- pulkan adanya enam keuntungan atau kegunaan potensial Teknologi Pembelajaran, yaitu bahwa Teknologi Pembelajaran membuat pembelajaran: produktif, individual, ilmiah, berdaya mampu tinggi, akrab, dan merata (Miarso, 1987: 10; Burton \& Lockee, 2000:1). ICT makes greater ability to learn, for example, distance learning permits students to get accreditations online from recognized university (Labelle, 2004:18). Pendapat hampir sama dikemukakan oleh Afzalnia (1990: 94). Dia menyebutkan enam keuntungan teknologi pembelajaran, yaitu:

- Instructional technology can increase the output of the educational system in term of both quality and quantity;

- Instructional Technology can individualize both instruction and learning;

- Instructional technology can place the development of instruction on a more scientific base;

- Instructional technology can use more powerful techniques to obtain planned objectives;

- Instructional technology can accelerate the learning process and make learning more easier than conventional methods;

- Instructional technology can provide easy access to information sources and existing knowledge for all people at different ages and with various interests.

Salah satu contoh manfaat teknologi pembelajaran untuk pembelajaran bidang sosial dapat dilihat pada hasil evaluasi implementasi penataran pembelajaran portfolio kewarganegaraan (civic) terhadap 63 orang guru SMP di DIY tahun 2002. Dengan menerapkan konsep dan prinsip teknologi pembelajaran dan dengan menggunakan produk ICT 
berupa presentasi komputer multimedia, OHP, VCD, Video, Audio, display portfolio, diperoleh hasil bahwa para guru dapat dengan mudah memahami isi penataran dan mampu menerapkan hasil penataran di lapangan (training by objective) (Gafur, 2003:66).

Dalam menerapkan konsep dan prinsip ICT dalam pendidikan dan pembelajaran, ada beberapa masalah, isu, ataupun tantangan yang perlu diperhatikan agar ICT benar-benar dapat membantu meningkatkan mutu pembelajaran secara optimal. Permasalahan dan tantangan dimaksud secara garis besar pada tataran makro meliputi perbedaan kondisi wilayah atau daerah, dan pada tataran khusus berkenaan dengan praktek atau pelaksanaan pendidikan di lembaga-lembaga pendidik

Terdapat perbedaan besar antar daerah atau sekolah dalam praktek penggunaan ICT untuk pembelajaran. Hal ini disebabkan oleh beberapa faktor, satu di antaranya karena perbedaan keterampilan pihak guru dalam menggunakan ICT. Faktor lain karena kurikulum pendidikan guru yang belum memasukkan ICT sebagai bagian integral dalam proses pembelajaran. Ketiadaan sarana dan prasarana penunjang ICT juga merupakan faktor penting penyebab bervariasinya lembaga-lembaga pendidikan dalam memanfaatkan ICT. Bagi banyak guru utamanya di pedesaan atau daerah terpencil, akses ke komputer atau produk teknologi pendidikan yang lain agaknya masih berupa impian. Sebaliknya bagi guru-guru di perkotaan telah banyak yang dapat memanfaatkan kemajuan ICT untuk pen- didikan seperti internet, komputer multimedia, VCD, DVD, dan sebagainya.

Tantangan utama penerapan ICT dalam pembelajaran adalah "both teachers and students are learning new skills related to ICT" (Unesco, 2003:20), padahal untuk menguasai keterampilan baru tersebut perlu waktu dan biaya yang tidak sedikit. Ditinjau dari segi sumber belajar atau komponen sistem pembelajaran masalah-masalah yang berkenaan dengan penerapan ICT dalam pembelajaran menyangkut pendidik/guru, pesan/kurikulum, perangkat keras, perangkat lunak, jaringan informasi, pengembangan paket pembelajaran, evaluasi, pendanaan, dsb. (Gafur, 1999:40; Gafur, 2001:92; APEID, 1994:19).

Untuk memecahkan masalah seperti diuraikan di depan, pertama-tama perlu diperhatikan faktor-faktor yang berpengaruh terhadap keberhasilan pemanfaatan ICT di sekolah. Banyak faktor yang mempengaruhi keberhasilan penerapan ICT di sekolah. Hasil indentifikasi Tim UNESCO Bangkok (2004: 13) menunjukkan adanya 5 faktor, yaitu: Vision and plan, supporting policies to facilitate the use of ICT, management of ICT resources, translation of laws into acceptable school-level regulation, and parents/ community. Sementara itu, NAACE (2002:1) menyebutkan bahwa faktorfaktor yang mempengaruhi efektivitas implementasi ICT di sekolah meliputi: "leadership and coordination, teaching and learning, managing infrastructure, and measuring success".

Dengan memperhatikan konsep dan prinsip ICT sebagai bidang garapan yang berupaya memecahkan masalah pendidikan dan pembelajaran melalui 
fungsi pengembangan dan pengelolaan sumber-sumber belajar, yang meliputi 5 bidang kegiatan, serta memperhatikan pula hasil identifikasi faktor-faktor yang berpengaruh terhadap keberhasilan pemanfaatan ICT dalam pembelajaran, maka pertanyaan-pertanyaan yang perlu dijawab dalam rangka mendeskripsikan potensi implementasi ICT dalam penelitian ini sebagai berikut.

- Bagaimanakah tingkat kompetensi ICT peserta didik dan tenaga kependidikan di SMA Negeri Kota Yogyakarta?

- Bagaimanakah model implementasi ICT yang dilaksanakan dalam rangka meningkatkan mutu pembelajaran?

- Hambatan-hambatan apa yang dihadapi dalam mengimplementasikan ICT di sekolah?

\section{METODE}

Penelitian dilaksanakan dengan mengambil lokasi di 11 SMA Negeri di Kota Yogyakarta. Dipilihnya SMA Negeri dengan pertimbangan sumber daya siswa (dari sisi usia dan keterampilan teknis) lebih eligible untuk penerapan ICT. Lagi pula pada beberapa sekolah negeri telah dirintis adanya sekolah bertaraf internasional (RSBI/SBI) yang dengansendirinya masalah ICT tentu mendapatkan perhatian penting.

Penelitian ini merupakan penelitian deskriptif dengan pendekatan kuantitatif. Penelitian deskriptif dimaksudkan untuk mengungkap gambaran objektif mengenai keadaan yang terdapat pada objek yang diteliti. Pendekatan deskriptif kuantitatif dimaksudkan untuk mendeskripsikan sasaran dengan menggunakan data berupa angka-angka. Di samping itu, dilakukan juga pendeskripsian secara verbal/kualitatif sasaran melalui kajian intensif dan terperinci terhadap suatu organisme, lembaga, atau gejala tertentu melalui suatu pengamatan atau analisis untuk menghasilkan data deskriptif kualitatif, yaitu data yang berupa kata-kata tertulis atau lisan dari orang, gejala atau perilaku yang diamati.

Sumber data dalam penelitian ini meliputi pengelola sekolah, guru, tenaga kependidikan, dan siswa yang menjadi responden penelitian. Siswa dari 11 SMA Negeri se-Kota Yogyakarta dipilih secaraacakuntuk menjadi responden penelitian. Keseluruhan responden yang terdiri dari kepala sekolah/wakil kepala sekolah, guru, tenaga administrasi, pengelola ICT dan siswa berjumlah 341 orang.

Pengumpulan data dilakukan dengan mengirimkan daftar pertanyaan dan melakukan wawancara kepada responden. Instrumen yang digunakan berupa dua buah angket dan pedoman wawancara. Angket pertama sebanyak 8 butir pertanyaan untuk mengidentifikasi kategori kompetensi ICT, sedangkan angket kedua 36 butir pernyataan untuk mengidentifikasi kompetensi ICT. Pedoman wawancara terdiri dari 60 butir pertanyaan. Wawancara dan pengamatan dilakukan untuk memperoleh data tentang model atau langkahlangkah implementasi ICT dan hambatan yang dihadapi sekolah dalam mengimplementasikan ICT untuk peningkatan mutu pembelajaran. 


\section{HASIL PENELITIAN}

Penelitian dilaksanakan pada bulan Mei sampai dengan November 2009 dengan mengambil tempat pada 11 SMA Negeri se Kota Yogyakarta. Sumber data yang menjadi responden penelitian ini terdiri dari siswa, guru, personel/ pengelola TI, dan Kepala Sekolah/Wakil Kepala Sekolah di SMA Negeri se Kota
Yogyakarta. Jumlah responden dari 11 sekolah untuk memperoleh data tentang nama sekolah, status, kategori kompetensi, dan tempat akses internet berjumlah 341 orang.

Hasil analisis data kuantitatif dapat disajikan sebagai berikut. Jumlah responden masing-masing sekolah nampak pada tabel berikut.

Tabel 1. Jumlah Responden dari Masing-masing SMA

\begin{tabular}{ccccc}
\hline SMA & Frequency & Percent & Valid Percent & $\begin{array}{c}\text { Cumulative } \\
\text { Percent }\end{array}$ \\
\hline SMAN 1 & 34 & 10.0 & 10.0 & 10.0 \\
SMAN 2 & 36 & 10.6 & 10.6 & 20.5 \\
SMAN 3 & 28 & 8.2 & 8.2 & 28.7 \\
SMAN 4 & 36 & 10.6 & 10.6 & 39.3 \\
SMAN 5 & 37 & 10.9 & 10.9 & 50.1 \\
SMAN 6 & 37 & 10.9 & 10.9 & 61.0 \\
SMAN 7 & 23 & 6.7 & 6.7 & 67.7 \\
SMAN 8 & 23 & 6.7 & 6.7 & 74.5 \\
SMAN 9 & 26 & 7.6 & 7.6 & 82.1 \\
SMAN 10 & 36 & 10.6 & 10.6 & 92.7 \\
SMAN 11 & 25 & 7.3 & 7.3 & 100.0 \\
Total & 341 & 100.0 & 100.0 & \\
\hline
\end{tabular}

Berdasar Tabel 1tersebut, responden terbanyak berasal dari SMA Negeri 5 dan SMA Negeri 6, masing-masing 37 orang $(10,9 \%)$ dari total responden. Responden paling sedikit berasal dari SMA 7 dan SMA 8 (6,7\%).

Tabel 2. Status Responden

\begin{tabular}{lcccc}
\hline \multicolumn{1}{c}{ Status Responden } & Frequency & Percent & Valid Percent & $\begin{array}{c}\text { Cumulative } \\
\text { Percent }\end{array}$ \\
\hline Siswa & 317 & 93.0 & 93.0 & 93.0 \\
Guru & 11 & 3.2 & 3.2 & 96.2 \\
Pengelola ICT & 5 & 1.5 & 1.5 & 97.7 \\
Kepala Sekolah & 1 & 0.3 & 0.3 & 97.9 \\
Tenaga Adminsitrasi & 7 & 2.1 & 2.1 & 100.0 \\
Total & 341 & 100.0 & 100.0 & \\
\hline
\end{tabular}

Cakrawala Pendidikan, Juni 2010, Th. XXIX, No. 2
Status responden, terdiri dari siswa, guru, pengelola ICT, kepala sekolah/ wakil kepala sekolah, dan tenaga administrasi. Rincian status responden dapat dilihat pada Tabel 2 berikut. 
Dari tabel tersebut nampak bahwa mayoritas responden berasal dari siswa 93\%. Berikutnya Guru (3,2\%), tenaga administrasi $(2,1 \%)$, pengelola ICT $(1,5 \%)$, dan kepala sekolah $(0,3 \%)$.

Kategori kompetensi ICT dibagi menjadi 5, yaitu: sangat rendah, rendah, sedang, tinggi dan sangat tinggi. Tabel berikut menunjukkan hasil analisis deskriptif kategori kompetensi ICT responden yang diperoleh dengan mengirimkan angket kepada mereka.

Tabel 3. Kategori Kompetensi ICT

\begin{tabular}{ccccc}
\hline Kategori & Frequency & Percent & $\begin{array}{c}\text { Valid } \\
\text { Percent }\end{array}$ & $\begin{array}{c}\text { Cumulative } \\
\text { Percent }\end{array}$ \\
\hline Sangat Rendah & 8 & 2.3 & 2.3 & 2.3 \\
Rendah & 54 & 15.8 & 15.8 & 18.2 \\
Sedang & 115 & 33.7 & 33.7 & 51.9 \\
Tinggi & 128 & 37.5 & 37.5 & 89.4 \\
Sangat Tinggi & 36 & 10.6 & 10.6 & 100.0 \\
Total & 341 & 100.0 & 100.0 & \\
\hline
\end{tabular}

Dari tabel 3 nampak bahwa kelima kategori kompetensi tersebut merata dijumpai pada responden. Yang termasuk kategori sangat rendah sedikit yaitu 8 orang $(2,3 \%)$, berikutnya kategori rendah 54 orang $(15,8 \%)$, kategori sedang 115 orang $(33,5 \%)$, kategori tinggi 128 $(37,5 \%)$ dan kategori sangat tinggi 36 orang $(10,6 \%)$. Jika dijumlahkan, responden yang termasuk kategori sedang sampai dengan tinggi termasuk mayoritas dari jumlah keseluruhan responden yaitu 279 orang (81,6 \%) dari 341 responden. Dengan demikian dapat dikatakan bahwa secara keseluruhan kompetensi ICT responden termasuk baik. Dengan kata lain, potensi untuk mengimplementasikan ICT di SMA se Kota Yogyakarta termasuk tinggi.

Mengenai tempat akses internet, teridentifikasi ada empat tempat yaitu di rumah, sekolah, ruang kelas, dan tempat lain seperti warnet atau tempattempat lain yang menyediakan hotspot. Dari Tabel 4 berikut dapat diketahui bahwa mayoritas responden melakukan akses internet di rumah sebanyak 154 orang $(45,2 \%)$, di tempat lain 130 orang $(38,1 \%)$, di sekolah 56 orang $(16,4 \%)$, dan terakhir di ruang kelas $1(0,3 \%)$.

Tabel 4. Tempat Akses Internet

\begin{tabular}{ccccc}
\hline Tempat & Frequency & Percent & Valid Percent & $\begin{array}{c}\text { Cumulative } \\
\text { Percent }\end{array}$ \\
\hline Rumah & 154 & 45.2 & 45.2 & 45.2 \\
Sekolah & 56 & 16.4 & 16.4 & 61.6 \\
Ruang Kelas & 1 & .3 & .3 & 61.9 \\
Tempat Lain Warnet & 130 & 38.1 & 38.1 & 100.0 \\
Total & 341 & 100.0 & 100.0 & \\
\hline
\end{tabular}


Menarik untuk dibahas, mengapa kebanyakan responden mendapatkan akses internet di rumah atau di tempat lain seperti warnet. Akses internet di sekolah hanya dilakukan oleh 16,4\% responden, bahkan akses internet di ruang kelas sangat sedikit dilakukan oleh reponden $(0,3 \%)$.

Adanya infrastruktur internet yang setiap saat siap dipergunakan merupakan salah satu petunjuk tingginya tingkat pemanfaatan ICT. Sehubungan dengan itu manakala responden lebih banyak mendapatkan akses internet di luar sekolah, bisa menimbulkan pertanyaan apakah karena waktu responden lebih banyak di luar sekolah atau karena sekolah belum menyediakan fasilitas yang memadai untuk akses internet. Sedikitnya akses internet di ruang klas dapat dimaklumi karena memang belum banyak sekolah yang menyediakan LAN atau hotspot yang menjangkau ruang kelas yang siap digunakan pada saat proses pembelajaran berlangsung.

\section{MODEL IMPLEMENTASI ICT}

Implementasi ICT pada umumnya telah dilaksanakan secara sistematis sesuai model atau langkah-langkah mulai dari desain, pengembangan/produksi, pemanfaatan, pengelolaan, dan diakhiri dengan evaluasi.

Secara rinci, model implementasi ICT yang dilaksanakan oleh 11 SMA Negeri se-kota Yogyakarta dapat dijelaskan sebagai berikut.

\section{Desain}

Kegiatan desain dalam implementtasi ICT mencakup identifikasi kemam- puan awal SDM, pengembangan sistem instruksional, strategi instruksional, dan penerapan prinsip-prinsip disain pesan. Dari hasil wawancara diperoleh data bahwa identifikasi kemampuan awal siswa telah dilaksanakan. Hasil identifikasi kemampuan awal siswa di bidang ICT pada umumnya sudah bagus. Siswa sudah terbiasa menggunakan TI terlebih dalam mengikuti mengikuti kelas ICT. Identifikasi kemampuan awal siswa tersebut dilakukan dengan menyebarkan angket dan mengamati siswa pada waktu praktikum. Terlihat banyak siswa yang membawa/mempunyai laptop sendiri.

Tiga butir disain yang belum jelas keterlaksanaannya, yaitu tentang pengembangan sistem instruksional, strategi instruksional, dan penerapan prinsip-prinsip desain pesan dalam merancang implementasi ICT untuk pembelajaran.

\section{Pengembangan}

Pengembangan ICT mencakup pengembangan audiovisual, media berbasis komputer, dan pengembangan media terpadu. Pada ke 11 SMA Negeri Yogyakarta,program-program ICT yang dikembangkan/diproduksi antara lain meliputi: e-learning, PowerPoint, website untuk pembelajaran. Program tersebut selalu di-update.

Dari hasil wawancara diperoleh informasi bahwa kebanyakan media yang dikembangkan adalah media berbasis komputer. Di samping itu, pengembangan multimedia yang dilaksanakan belum terintegrasi dengan sistem pembelajaran. Belum ada misalnya produk 
multimedia untuk seluruh mata pelajaran yang dikemas dalam bentuk VCD atau yang di-upload di website.

\section{Pemanfaatan}

Beberapa bentuk pemanfaatan multimedia untuk pembelajaran, misalnya multimedia sebagai sistem, multimedia sebagai alat bantu ajar, multimedia untuk suplemen, dan media untuk pengayaan.

Dari hasil wawancara diperoleh informasi bahwa bentuk-bentuk upaya yang dilakukan sekolah untuk memanfaatkan ICT baru pada pemanfaatan multimedia sebagai alat bantu ajar (teaching aids), suplemen, dan pengayaan. Multimedia belum digunakan sebagai sistem yang terintegrasi dengan pengembangan sistem instruksional. Kegiatan pemanfaatan dilakukan dengan jalan pembiasaan pemanfaatan ICT yang dilakukan melalui peningkatan SDM lewat pelatihan, membuat media pembelajaran, membuat audio video, web, dan lain-lain. Sudah banyak guru menggunakan IT untuk pembelajaran. Murid juga dilatih memanfaatkan ICT untuk pembelajaran. Dari hasil pelatihan tersebut murid dapat: melihat materi dari guru, mengirim tugas, mencari materi, forum belajar, dll. Bagi karyawan/ pegawai administrasi, pemanfaatan TI berupa pemanfaatan SISKO (Sistem Informasi Sekolah) seperti memasukan data base siswa, guru, data nilai, raport. Untuk peningkatan pemanfaatan teknologi informasi dalam pembelajaran, sekolah mengadakan training komputer dasar, pelatihan web, pelatihan ICT, baik kepada guru, murid, tenaga administrasi, dan pengelola TI.
Pelembagaan sudah ada yaitu dengan dibentuk ICT Center, tetapi peraturan yang secara tegas belum ada. Sekolah baru sebatas menganjurkan, mendorong, dan memotivasi untuk menggunakan ICT.

\section{Pengelolaan}

Pengelolaan ICT menyangkut pengelolaan proyek, pengelolaan pusat sumber belajar, pengelolaan sistem penyampaian, dan pengelolaan sistem informasi. Pada SMA Negeri di kota Yogyakarta, pengelolaan ICT diwujudkan dalam bentuk pusat multimedia, ruang multimedia,adanya koordinator TI yang dikepalai oleh kepalasekolah, di bawahnya wakil kepala sekolah urusan sarana prasarana, koordinator ICT.

Dari hasil wawancara terhadap responden, belum ada kejelasan penggunaan ICT sebagai sarana sistem penyampaian pembelajaran yang dan pengelolaan sistem informasi yang dikelola oleh badan atau unit tersendiri. Juga mekanisme peminjaman hardware dan software ICT belum berjalan baik. Unit ICT belum sepenuhnya mengelola data base atau SIM sekolah.

\section{Evaluasi}

Evaluasi dalam ICT meliputi evaluasi kriteria acuan, evaluasi formatif, dan evaluasi sumatif. Evaluasi kriteria acuan dimaksudkan untuk mengukur tercapai tidaknya tujuan. Evaluasi formatif dilaksanakan pada saat proses sedang berlangsung untuk mengetahui hambatan yang ada dan untuk perbaikan. Evaluasi sumatif untuk mengukur tingkat keberhasilan. 
Sekolah juga mengadakan analisis kebutuhan untuk mengetahui seberapa tinggi tingkat kebutuhan sekolah terhadap TI. Hasil identifikasi menunjukkan bahwa TI sangat dibutuhkan, dalam pembelajaran. TI sangat penting, oleh karena itu sekolah perlu senantiasa berusaha memfasilitasi guru dan siswa. Dengan pemanfaatan TI dalam pembelajaran, kegiatan siswa lebih aktif, tidak berpusat pada guru. Perangkat yang dibutuhkan untuk implementasi TI yang mendesak, misalnya, Internet, TV pembelajaran, CD/media pembelajaran.

Hasil penilaian terhadap pemanfaatan TI antara lain: lebih mempermudah dalam Analisis SWOT secara sistematis belum dilaksanakan, tetapi analisis secara umum sudah dilakukan untuk mengetahui kekuatan, kelemahan, tantangan, dan peluang untuk pengembangan ICT.

Dalam kegiatan evaluasi belum dilaksanakan secara teratur evaluasi formatif maupun sumatif. Evaluasi formatif dimaksudkan untuk mengetahui keterlaksanaan implementasi ICT sesuai rencana. Hasil evaluasi formatif digunakan untuk perbaikan. Evaluasi sumatif dimaksud untuk mengetahui efektivitas ICT untuk meningkatkan mutu pembelajaran.

\section{HAMBATAN}

Hambatan-hambatan dalam mengimplementasikan ICT mencakup SDM, infrastruktur, hardware, dan software. Hambatan di bidang sumber daya manusia mencakup kuantitas dan kualitas. Jumlah tenaga pengelola ICT yang memiliki kompetensi di bidang ICT belum mencukupi. Belum tersedia dalam jumlah yang cukup tenaga yang berkualifikasi sebagai profesional, spesialis, dan teknisi sumber belajar multimedia. Belum semua SDM antusias, termotivasi (lebih-lebih tenaga guru senior), dan memiliki kompetensi sesuai yang diharapkan untuk mengimplimentasikan ICT dalam rangka peningkatan mutu pembelajaran.

Hambatan di bidang infrastruktur: Belum semua sekolah memiliki infrastruktur (misalnya kabel LAN ke seluruh ruang kelas) yang diperlukan untuk mengimplementasikan ICT secara optimal. Belum tersedia gedung atau ruang yang memadai untuk mengelola pengembangan ICT. Belum semua sekolah memiliki hardware lengkap baik mengenai kualitas maupun kuantitas yang diperlukan untuk implementasi ICT. Hardware yang out of date mengalami kesulitan dalam meng-upgrade karena sudah tidak kompatibel dengan software mutakhir. Masalah mahalnya software resmi/original menjadi hambatan untuk mengembangkan/ memproduksi program-program ICT.

\section{KESIMPULAN}

- Kategori kompetensi ICT meliputi 5 kategori, yaitu: sangat rendah, rendah, sedang, tinggi dan sangat tinggi. Yang termasuk kategori sangat rendah yaitu 8 orang (2,3\%), berikutnya kategori rendah 54 orang $(15,8 \%)$, kategori sedang 115 orang $(33,5 \%)$, kategori tinggi $128(37,5 \%)$ dan kategori sangat tinggi 36 orang $(10,6 \%)$. Jika dijumlahkan, responden yang termasuk kategori sedang sampai tinggi termasuk mayoritas dari jumlah ke- 
seluruhan responden yaitu 279 orang $(81,6 \%)$ dari 341 responden. Dengan demikian dapat disimpulkan bahwa secara keseluruhan kompetensi ICT responden termasuk baik atau tinggi. Dengan kata lain, potensi untuk mengimplementasikan ICT di SMA se Kota Yogyakarta termasuk tinggi karena didukung oleh SDM yang memiliki kompetensi tinggi.

- Implementasi ICT pada umumnya telah dilaksanakan secara sistematis dengan mengikuti model mulai dari disain, pengembangan/produksi, pemanfaatan, pengelolaan, dan evaluasi. Namun terdapat beberapa langkah pada masing-masing tahap yang belum dilaksanakan secara jelas, misalnya pengembangan sistem pembelajaran yang terintegrasi dengan ICT, pemanfaatan ICT sebagai suatu sistem, pengelolaan sistem penyampaian, dan evaluasi fektifitas implementasi ICT secara menyeuruh.

- Hambatan di bidang sumber daya manusia mencakup kuantitas dan kualitas. Jumlah tenaga pengelola ICT yang memiliki kompetensi di bidang ICT belum mencukupi. Belum tersedia dalam jumlah yang cukup tenaga yang berkualifikasi sebagai profesional, spesialis, dan teknisi sumber belajar multimedia. Belum semua SDM antusias, termotivasi (lebih-lebih tenaga guru senior), dan memiliki kompetensi sesuai yang diharapkan untuk mengimplimentasikan ICT dalam rangka peningkatan mutu pembelajaran.

- Hambatan di bidang infrastruktur: Belum semua sekolah memiliki infrastruktur (misalnya kabel LAN ke seluruh ruang kelas) yang diperlukan untuk mengimplementasikan ICT secara optimal. Belum tersedia gedung atau ruang yang memadai untuk mengelola pengembangan ICT.

- Belum semua sekolah memiliki hardware lengkap baik mengenai kualitas maupun kuantitas yang diperlukan untuk implementasi ICT. Hardware yang out of date menglami kesulitan dalam mengupgrade karena sudah tidak kompatibel dengan hardaware mutakhir.

- Masalah mahalnya software resmi/original menjadi hambatan untuk mengembangkan/memproduksi program-program ICT.

\section{SARAN}

- Perlu diupayakan agar semua personalia di SMA dapat meningkatkan kompetensinya di bidang ICT melalui kegiatan penataran, workshop, seminar, mengikuti pendidikan lanjut di bidang ICT, dan sebagainya. Jumlah personalia yang mengelola program ICT perlu pula ditambah melalui pola reqruitmen yang sistematis sesuai kompetensi yang diperlukan. Sekolah perlu mengupayakan dibangunnya sebanyak mungkin jaringan, agar semua personalia dapat mengakses internet di sekolah.

- Setiap langkah model implementasi/ pengembangan perlu dilaksanakan dengan tepat. Misalnya pada tahap desain perlu dikembangkan sistem instruksional terpadu yang mengintegrasikan ICT dalam proses pembelajaran; pada tahap evaluasi, perlu dilaksanakan supervisi, monitoring, dan penilaian terhadap kelancaran 
dan efektifitas penerapan ICT untuk pembelajaran. Selanjutnya, hasil evaluasi tersebut digunakan untuk memperbaiki hal-hal yang belum berjalan sebagaimana mestinya.

- Hambatan berkenaan dengan SDM yang enggan meningkatkan diri akan kompetensinya di bidang ICT perlu diatasi misalnya dengan menerapkan sistem reward and punishment. Hambatan berkenaan dengan jumlah, perlu dipecahkan dengan pola reqruitment yang terencana.

- Hambatan yang berkenaan dengan infrastruktur, hardware, dan software perlu diatasi melalui perencanaan yang tersistem dengan mengedepankan pada skala prioritas untuk pengadaannya.

\section{UCAPAN TERIMA KASIH}

Penelitian ini dapat berlangsung dengan relatif lancar karena adanya sejumlah bantuan dari beberapa pihak. Oleh karena itu, dalam kesempatan ini peneliti ingin menyampaikan rasa terimakasih yang setulus kepada pihak DP2M Dikti sebagai pemberi dana penelitian. Terakhir, kepada Redaktur dan staf Jurnal Cakrawala Pendidikan UniversitasNegeriYogyakarta yang telah memberi kesempatan untuk mempublikasikan artikel hasil penelitian ini.

\section{DAFTAR PUSTAKA}

Gafur, Abdul. 2001. “Pendidikan dalam Tantangan Teknologi ICT". Cakrawala Pendidikan: Majalah Ilmiah Kependidikan. Mei 2001 Th. XX. No.2. pp. 90 - 95.
1999. “Peranan Alat Bantu Ajar dalam peningkatan Mutu Pendidikan." Teknologi dan Informasi Pendidikan (TEKNODIK). Vo. IV. No. 6. April 1999. (pp. $40-44$ ).

. 2003. “Evaluasi Implementasi Hasil Penataran Portofolio Kewargenagaraan (Civic) Guru PPkn SLTP di Propinsi Daerah Istimewa Yogyakarta". Jurnal Teknologi Pembelajaran: Teori dan Penelitian. Tahun 11, No. 2, Oktober 2003, pp. $66-79$.

AECT. 1977. The Definition of Educational Technology. Washington D.C.: AECT.

Reza, Afzalnia. 1990. "The Benefits of Educational Technology". Educational Technology Research and Development (ETRD). Vol.38 No.3 pp. $93-96$.

Akhori, Kanji \& Kumar, K.L. 1999. "Evaluation of a Multimedia Package on Pedagogical Design and Display Visual". International Journal of Educational Technology. Vo. 1, No. 1.

APEID. 1994. Final report of the Asia and the Pacific Seminar on Educational Technology. Tokyo: The Japan National Commision for UNESCO.

A Naace Publication. 2004. Implementing ICT A Guide to Implementing ICT in School of the UK. Diambil pada tanggal 30 November 2004 dari 
http://www.naace.org//mpict/mai $\underline{\text { n.html. }}$

Backhouse, Bruce. 2003. “Information \& Communication Technology Integration: Beyond the Early Adopters". Technology Trends (Tech Trends). Mayđune 2003 .Vol. 47, No. 3. pp. $5-9$.

Burton, John \& Lockee, Barbara. 2000. "Building Equity through Learning: Instructional Technology for Rural Community Development". International Journal of Educational Technology. July, 2000, Vol. 2, No. 1.

Curriculum Information Technolgy Integration (CITI) Project. (http://www.edu.gov.mb.ca/ks4/tech/citi/ind ex.html).

Glenn, A. \& Shinohara, J. Building. 2003. Capacity of Teachers/Facilitator in Technology-Pedagogy Integration for Improved Teaching and Learning. Bangkok: UNESCO.

Gagne, Robert M. 1997. The Conditions of Learning. New York: Holt, Rinehart and Winston.

Harry B. Santoso. 2007: 2. TIK. Dalam http://dl2.cs.ui.ac.id/harrybs/ГІК. pdf Diakses pada tanggal 13 Desember 2007.

Heinich, et al. 1996 Instructional Media and Technologies for Learning. New Jersey: Printice- Hall, Inc.
Henderson dan Horton. 2004. "The TIK Question and Answer Book". dalam Sinar Harapan versi online dengan alamat http:/wwww.sinarharapan.co.id/ekonomi/mandiri/2 004/0217/man01.html Diakses pada tanggal 13 Desember 2007.

Hepp, K., Hinostroza, E., Laval, E., et al. 2004. Technology in Schools: Education, ICT and the Knowledge Society.

Heuchan, Jadanne, etal.2002. “Exploring Website by Western Australian Schools. International Journal of Educational Technlogy, Vol.3. No.3.

Sidi, Indrajati. 2002. Konsep Pendidikan Berorientasi Kecakapan Hidup (Life Skill) melalui Pendekatan Pendidikan Berbasis Luas. Jakarta: Ditjen Dikdasmen.

Januszewski,Alan.2001.Educational Technology: the Development of a Concept. New Jersey: Englewood Publ.

Kar Tin Lee. 2002. Student's Usage and Perception of the ELITE Programme. IJET November 2002, Vol. 3 No.1.

Labelle, R. 2005. ICT Policy Formulation andE-Strategy Development A Comprehensive Guidebook. Bangkok. UNDP-Asia Pasific Development Information Programme.

Lim, Cher P. 2002. “Online Learning in Schools: Some Lessons from Pole- 
Vaulting". International Journal of Educational Technlogy, Vol.3. No.1.

Lockheed, M.E. and Hanushek, E.A. 1996. "Concepts of Educational Efficiency and Effectiveness". International Encyclopedia of Educational Technology. New York: Pergamon.

Miarso, Yusuf Hadi. 1987. Landasan Falsafah dan Teori Teknologi Pendidikan. Jakarta: Fakultas Pasca Sarjana UNJ.

Miller, Karen Hughes. 2005. One Course, Two Ways: Lessons learned from Teaching the Same Graduate Course Online and Face-to-Face.

NAACE. 2004. Implementing ICT A Guide to Implementing ICT in School of the UK. Diambil pada tanggal 30 November 2004, dari http:/www.naace.org/mpict/mai n.html.

Nickerson, Reymond S. \& Zodhiates, PhilipP.1991. “Technology in Education: Looking toward 2020". Educational Technology Research and Development. Vol. 39, No. 3, 1991.

Ray, Beverly. 2002. "Personal Digital Assistants (PDA) in the Classroom: Integration Strategies for Educators". International Journal of Educational Technlogy, Vol 3. No.1. tional Design and Technology. New Jersey: Pearson Education, Inc.

Robinson, B. \& Passi. 2004. Final Report The Workshop on the Development of Guideline on Teacher in ICT Integrated and Standards for Competency in ICT. Bangkok: UNESCO.

Seels, Barbara B. \& Richey, Rita C. 1994. Instructional Technology: The Definition and Domains of the Field. Washington D.C.: Association for Educational Communications \& Technology (AECT).

UNESCO. 2004. Integrating ICTs in Education: Lessons Learned. Bangkok: UNESCO PBL

. 2004. Developing and Using Indicators of ICT Use in Education. Bangkok: UNESCO PBL. . 2004. Indicators for Assessing ICT Impact in Education. Bangkok.

UNESCO Asia \& Asia and Pacific Regional Bureau UNESCO. 2003. Building Capacity of Teachers/Facilitators in Technology-Pedagogy Integration for Improved Teaching and Learning. Bangkok: UNESCO Bangkok.

Reiser, Robert A. \& Dempsey, John V. 2002. Trends and Issues in Instruc- 